\title{
Improving the Efficiency of Organic Fertilizer and Nitrogen Use via Air Plasma and Distributed Renewable Energy
}

\author{
R. Ingels ${ }^{1, *} \&$ D.B. Graves ${ }^{2}$ \\ ${ }^{1} \mathrm{~N}_{2}$ Applied As, Beddingen 20250 Oslo, Norway; ${ }^{2}$ University of California at Berkeley, Berkeley, \\ California 94720 \\ *Address all correspondence to: Rune Ingels, N2 Applied, Vestsida 71, 3622 Svene, Norway; Tel. +4748142354, rune. \\ ingels@n2applied.no
}

\begin{abstract}
Synthesis of reactive forms of nitrogen such as ammonia is important in modern agricultural productivity, but present agricultural technology uses reactive nitrogen inefficiently, leading to numerous and growing environmental problems. Animal, human, and food waste all contain significant quantities of organic nitrogen that are transformed into ammonia $\left(\mathrm{NH}_{3}\right)$ by bacterial degradation of organic waste. If not captured, this volatile form of reactive nitrogen is lost to the environment, reducing $\mathrm{N}$ content and thus the agricultural value of organic waste. Furthermore, ammonia loss to the environment initiates a cascade of environmental problems. Nonequilibrium air plasma technology creates reactive nitrogen that can be readily converted to dilute aqueous nitric acid solutions. If mixed with decaying organic waste, $\mathrm{NH}_{3}$ loss is greatly reduced via the formation of involatile ammonium nitrate, a potent nitrogen fertilizer. Air plasma technology for fixed nitrogen manufacture is currently limited only by the availability of electricity and the energy efficiency of the process. The price of electricity via distributed renewable routes such as solar photovoltaic or wind turbines is rapidly decreasing. Increasingly, inexpensive wind and solar power sources, coupled with recent advances in air plasma energy efficiency, suggest that this technology could have a significant role in improving nitrogen use efficiency and reducing environmental and other threats associated with the current system.
\end{abstract}

KEY WORDS: reactive nitrogen, air plasma, acidification, nitric acid, ammonia loss, organic fertilizer, Birkeland, organic waste

\section{INTRODUCTION}

Reactive (or "fixed") nitrogen $\left(\mathrm{N}_{\mathrm{r}}\right)$, an essential component in synthetic fertilizers, is currently almost exclusively supplied via a chemical synthesis process (Haber-Bosch [HB]) developed in Germany in the first decade of the 20th century. $\mathrm{H}_{2}$, usually extracted from natural gas via steam reforming, is combined with $\mathrm{N}_{2}$ from the air in a high-pressure high-temperature catalytic process to create $\mathrm{NH}_{3}$. Ammonia can then be used in subsequent steps to make various types of fertilizer components, but the initial transformation of very stable $\mathrm{N}_{2}$ molecules into reactive $\mathrm{NH}_{3}$ is the key step. ${ }^{1}$

The importance of this process, difficult to exaggerate, has deservedly received much attention. Figure 1 illustrates the correlation between world population and $\mathrm{N}_{\mathrm{r}}$ production through the year $2000 .^{2}$ It is estimated that nitrogen fertilizer generated via HB increased agricultural productivity sufficiently to sustain nearly $50 \%$ of the world's 


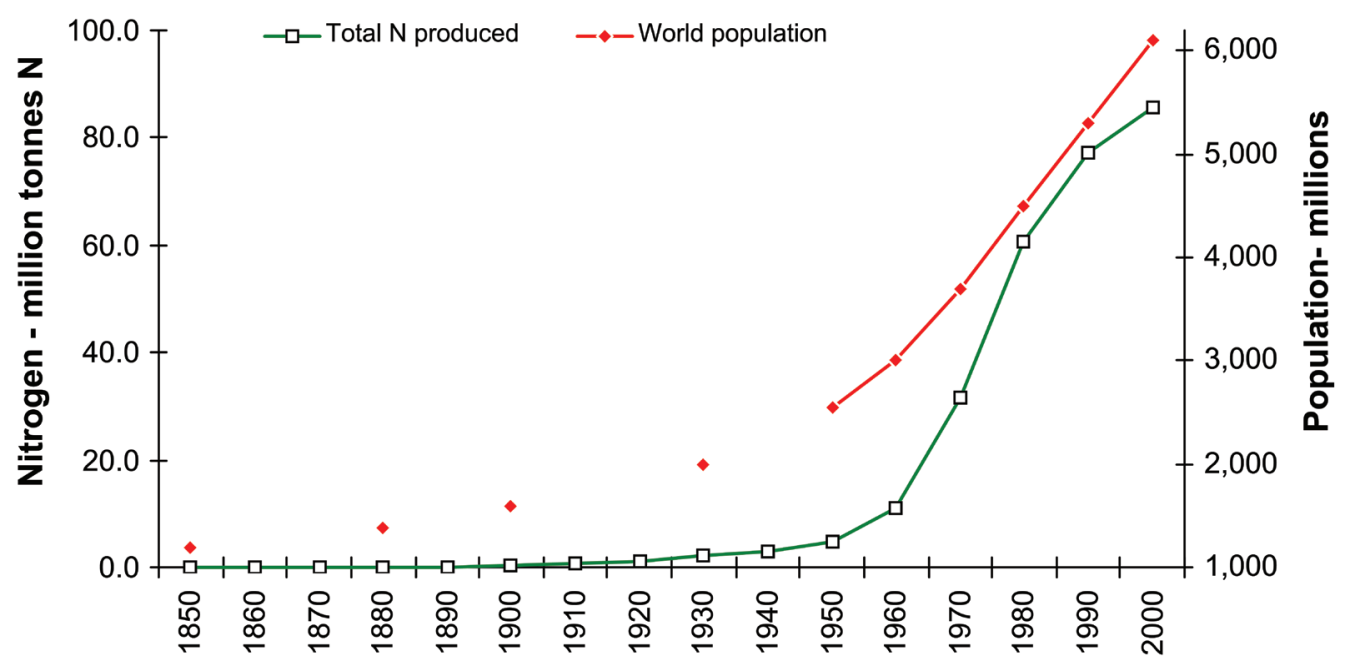

FIG. 1: World population growth follows reactive nitrogen production. ${ }^{2}$

population as of $2008 .^{3}$ This process accounts for $\sim 1 \%$ of total world energy use, and $\sim 3 \%-5 \%$ of worldwide conversion of natural gas is used to make the $\mathrm{H}_{2}$ needed for the process. ${ }^{1,2}$ Estimates generally suggest that world population will rise to $\sim 9$ billion by 2050 and that an increasing fraction of this larger population will likely demand diets with higher amounts of animal products. This anticipated increase in the population will therefore correspondingly increase the dependency on fertilizer inputs to maintain food production..$^{1-3}$ Together, these changes are expected to require a corresponding rise in $\mathrm{N}_{\mathrm{r}}$ production of $\sim 40 \%-50 \%$ by 2050 .

HB ammonia-manufacturing energy efficiency has progressed remarkably during the century since it was originally developed, and the basic process has remained essentially unchanged. A key figure of merit in the process is the amount of energy needed per mass of $\mathrm{N}_{\mathrm{r}}$ formed. Figure 2 plots how this index has dropped since the early part of the 20th century. The first HB manufacturing plants consumed well over $100 \mathrm{GJ} / \mathrm{t} \mathrm{N}{ }^{2}$ Smil points out that the thermodynamic minimum energy needed to form $\mathrm{NH}_{3}$ from the elementary reactants is $\sim 24 \mathrm{GJ} / \mathrm{t}$ of $\mathrm{N}$ produced. ${ }^{2,4}$ Furthermore, the largest, most energyintegrated, and therefore most energy-efficient ammonia plants now operate at $\sim 33 \mathrm{GJ} / \mathrm{t}$ of $\mathrm{N}$, remarkably close to this limit.

The success of the HB process and its key role in sustaining human population is undeniable, but some serious problems associated with the current situation exist, and the anticipated growth in demand for N-based synthetic fertilizer portends even more challenges for the future. Many (but not all) of the most serious issues center around the fact that human perturbation of the global nitrogen cycle has become quite significant, and this leads to numerous environmental problems. The phenomenon of human perturbation to the nitrogen cycle is illustrated in Table 1, which lists estimated sources of environmental $\mathrm{N}_{\mathrm{r}}$ as of $2010 .^{5}$ Approximately half of the flow of reactive nitrogen in the environment is 


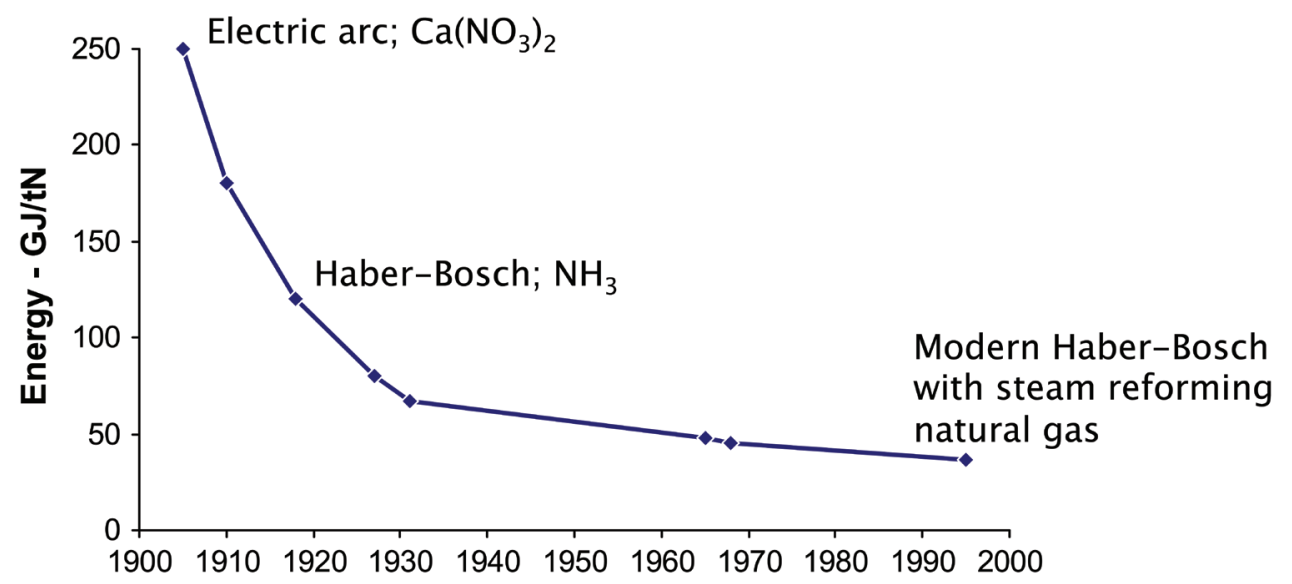

FIG. 2: Progress in efficiency improvements of energy use for nitrogen fixation. Modern Haber-Bosch $\mathrm{NH}_{3}$ manufacturing is highly optimized. ${ }^{2}$

now due to human (anthropogenic) sources.

A key point in the argument in favor of alternative approaches for creating and managing $\mathrm{N}$ fertilizers is that the efficiency of use of $\mathrm{N}_{\mathrm{r}}$ added for agricultural purposes is quite low. This is the main focus of a recent comprehensive report ${ }^{6}$ that, in regard to both phosphorous and nitrogen nutrients, states

"The efficiency of nutrient use is very low: considering the full chain, on average more than $80 \%$ of $N$ and $25 \%-75 \%$ of $P$ consumed (where not temporarily stored in agricultural soils) end up lost to the environment, wasting the energy used to prepare them, and causing pollution through emissions of greenhouse

TABLE 1: Global rates of nitrogen fixation as of 2010.

\begin{tabular}{ll}
\hline Source & Amount (Tg/yr) \\
\hline Nonanthropogenic & \\
Biological nitrogen fixation (land) & $58 \pm 50 \%$ \\
Biological nitrogen fixation (oceans) & $140 \pm 50 \%$ \\
Lightning & $5 \pm 50 \%$ \\
Total & 203 \\
Anthropogenic & \\
Combustion & $30 \pm 10 \%$ \\
Fertilizer production & $120 \pm 10 \%$ \\
Biological nitrogen fixation (agriculture) & $60 \pm 30 \%$ \\
Total & 210 \\
Overall total & 413 \\
\hline
\end{tabular}

From Fowler et al. ${ }^{5}$ 
gas $(\mathrm{GHG})$ nitrous oxide $\left(\mathrm{N}_{2} \mathrm{O}\right)$ and ammonia $\left(\mathrm{NH}_{3}\right)$ to the atmosphere, plus losses of nitrate $\left(\mathrm{NO}_{3}^{-}\right)$, phosphate $\left(\mathrm{PO}_{4}^{3-}\right)$ and organic $\mathrm{N}$ and $\mathrm{P}$ compounds to water."

Figure 3 partially illustrates the flows of reactive nitrogen associated with human food consumption. A more complete illustration of the current understanding of this nitrogen mass balance can be found in Sutton et al. ${ }^{6}$ Figure 3 shows that $\sim 164 \mathrm{Tg} / \mathrm{N}_{\mathrm{r}} / \mathrm{yr}$ flows into agricultural soil and fish, consisting of $120 \mathrm{Tg} / \mathrm{yr}$ as fertilizer and $60 \mathrm{Tg} / \mathrm{yr}$ in biological nitrogen fixation (BNF; cf. Table 1) plus $\sim 4 \mathrm{Tg} / \mathrm{yr}$ in the form of fish input to human nutrition. Of this, $164 \mathrm{Tg} / \mathrm{yr}$ food waste, human waste, and livestock waste (not associated with crops and grasses) amounts to $54 \mathrm{Tg} / \mathrm{yr}$. Virtually none of this "waste" $\mathrm{N}_{\mathrm{r}}$ is currently recycled to agricultural fields; this is the $\mathrm{N}_{\mathrm{r}}$ that should be recoverable, at least in part, by the proposed technology.

In addition to the obvious inefficiencies associated with the lack of $\mathrm{N}_{\mathrm{r}}$ recycling, many environmental problems are associated with the excess $\mathrm{N}_{\mathrm{r}}$ released into the environment. ${ }^{7}$ In particular, "nitrogen cascade" can result in a series of damaging reactions that occur in the environment following the release of $\mathrm{N}_{\mathrm{r}}$. Each $\mathrm{N}_{\mathrm{r}}$ atom released into the environment leads to eutrophication (excess fertilization) and acidification of ecosystems on land and water, which leads to negative effects on human health and climate. ${ }^{5}$ Some environmental analysts have even suggested that human perturbation of the natural nitrogen cycle has exceeded the safe "planetary boundary," and that, coupled with other environmental insults, may lead to irreversible degradation of the earth's environment. ${ }^{8}$

The problems associated with $\mathrm{N}_{\mathrm{r}}$ manifest differently in different parts of the world. For example, it has been argued that in some regions such as parts of India, government subsidies encourage improper and/or excessive use of synthetic fertilizer but it is organic fertilizers that are needed to restore soil fertility. ${ }^{9}$ In sub-Saharan Africa, parts of Latin America, and other locations in the developing world, a lack of synthetic fertilizer due to cost and infrastructure limitations can lead to soil, nutrient, and organic matter depletion, resulting in declining agricultural yields and increasing pressure to open undeveloped land for agriculture. In addition, fertilizer costs are closely tied to the price of fossil fuels, especially natural gas. Although natural gas prices are currently at relatively low levels (at least in the United States), it is possible that this will reverse in the not-too-distant future,$^{10}$ possibly threatening food supplies that rely on relatively inexpensive synthetic fertilizer made from fossil fuels.

Alternatives to conventional HB manufacture include replacing $\mathrm{H}_{2}$ production via steam reforming of methane with water electrolysis. Eliminating natural gas from the synthesis process would have the advantage of decoupling $\mathrm{NH}_{3}$ manufacturing costs from natural gas availability, constraints, and price fluctuations. Although a relatively mature technology, $\mathrm{H}_{2}$ production via water electrolysis is estimated to consume approximately three times as much energy, compared with conventional steam reforming of methane in the manufacture of ammonia. ${ }^{2}$ An attractive alternative may be supplying electrical energy for electrolysis via renewable energy sources. Additionally, $\mathrm{CO}_{2}$ emissions associated with $\mathrm{H}_{2}$ manufacturing plants would be considerably reduced as 


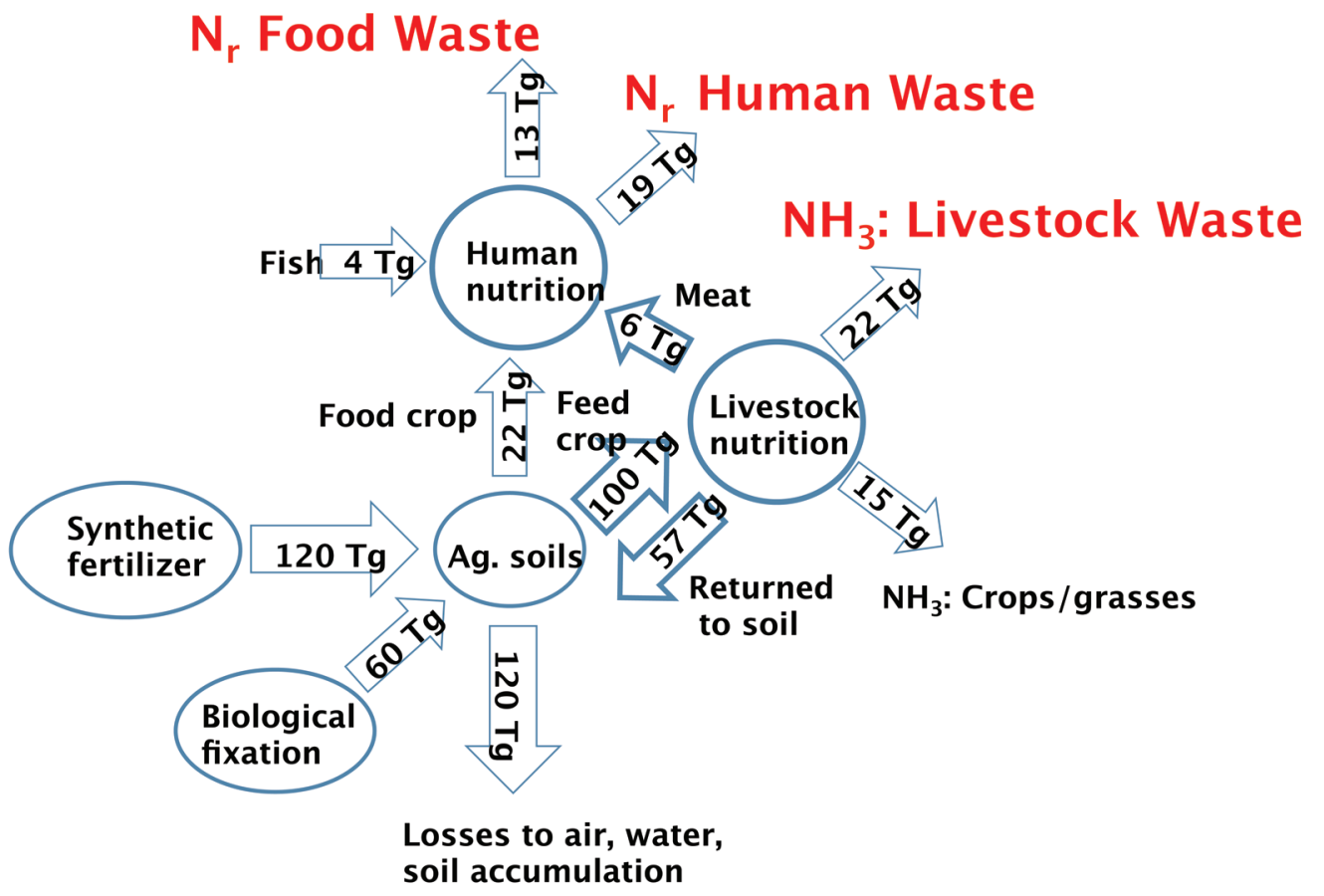

FIG. 3: Partial summary of global flows of reactive nitrogen, demonstrating the importance of food, human, and livestock waste. ${ }^{6} 1 \mathrm{Mt}=1 \mathrm{Tg}$.

well. The relatively technically complex, capital-intensive, high-pressure, and hightemperature catalytic process reacting in $\mathrm{H}_{2}$ and $\mathrm{N}_{2}$ to form $\mathrm{NH}_{3}$ would remain the same with this alternative, and the problems noted above regarding excess nutrient use, $\mathrm{NH}_{3}$ pollution, or inadequate supply and excessive costs in certain parts of the world would mostly remain.

Electrochemical methods to directly manufacture $\mathrm{NH}_{3}$ at atmospheric pressure have also been explored, as recently reviewed; ${ }^{11}$ however, these authors state that electrochemical $\mathrm{NH}_{3}$ synthesis methods are still in the early stages of development, and direct comparisons to HB cannot yet be made. We conclude that no technology in place nor in any reasonably near stage of development can replace HB.

We outline below an approach that does not attempt to replace HB, but rather, aims to improve the efficiency of $\mathrm{N}_{\mathrm{r}}$ use, therefore complementing the technology in use today. The proposed technology does not claim to solve all problems associated with $\mathrm{N}_{\mathrm{r}}$, but it could make a significant difference in ameliorating certain issues.

\section{IMPROVING NITROGEN USE EFFICIENCY THROUGH AIR PLASMA TECHNOLOGY}

Volatile $\mathrm{NH}_{3}$ is created when bacteria break down organic forms of nitrogen in proteins, 
nucleic acids, and amino acids. Acidifying organic waste to reduce $\mathrm{NH}_{3}$ losses by lowering $\mathrm{pH}$ is a well-known process to minimize or eliminate this loss, but is not widely used primarily because of cost considerations associated with equipment needed to handle acids safely. ${ }^{12}$ Sulfuric acid is the more common acid used for this purpose, because it is generally the least costly. Sulfuric acid is currently approved for use in manure acidification in Demark, and several other European nations are investigating this technology.

The overall reaction (using nitric acid) can be written as follows:

$$
\mathrm{NH}_{3}+\mathrm{HNO}_{3} \rightarrow \mathrm{NH}_{4} \mathrm{NO}_{3} \text {. }
$$

The method we propose starts with electrically powered air plasma creating nitric oxide (NO). NO is readily oxidized under atmospheric air conditions to form $\mathrm{NO}_{2}$. When $\mathrm{NO}_{2}$ is dissolved in water, $\mathrm{HNO}_{3}$ (in aqueous phase, nitrate anion $\mathrm{NO}_{3}^{-}$) is primarily created. We envision using this aqueous $\mathrm{NO}_{3}^{-}$to treat nitrogen-containing organic waste such as animal or other $\mathrm{N}_{\mathrm{r}}$-containing waste, reducing the $\mathrm{pH}$ to convert otherwise volatile $\mathrm{NH}_{3}$ to involatile ammonium nitrate (i.e., $\mathrm{NH}_{4} \mathrm{NO}_{3}$ ) as shown in Eq. (1).

A schematic of the air plasma to nitric acid process is illustrated in Figure 4. In this scenario, air plasma is generated using renewable electrical power (solar photovoltaic and/or wind turbines), but of course using renewable sources of electricity is not strictly necessary. However, it seems likely that this will be the most economical way to power the plasma device. Advantages to this approach are discussed below.

How much $\mathrm{N}_{\mathrm{r}}$ might be available in the form of $\mathrm{NH}_{3}$ that could be captured this way? Figure 3 summarizes how $\mathrm{N}_{\mathrm{r}}$ introduced into the agricultural system is lost in the forms of food waste (13 Tg/N/yr), human waste (19 Tg/N/yr), and livestock waste (22 Tg/N/yr in the form of $\mathrm{NH}_{3}$ ). For example, the loss of $\mathrm{NH}_{3}$ can reduce the nitrogen content of slurry manure applied as fertilizer by as much as $50 \%$ or more. ${ }^{12}$ The combined losses of $\mathrm{N}_{\mathrm{r}}$ from just these three sources of organic nitrogen amount to $54 \mathrm{Tg} / \mathrm{N} / \mathrm{yr}$. In principle, capturing volatile $\mathrm{NH}_{3}$ emissions using acidification of organic waste in each of these areas is possible, for example, in anaerobic digestion of food and human waste. Furthermore, use of nitric acid doubles the $\mathrm{N}$ content of organic fertilize because for each molecule of $\mathrm{NH}_{3}$ retained as $\mathrm{NH}_{4}^{+}$, a molecule of $\mathrm{NO}_{3}^{-}$is added. If only $10 \%-20 \%$ of organic forms of $\mathrm{N}_{\mathrm{r}}$ is retained by this process, leading to $20 \%-40 \%$ more nitrogen in recycled organic fertilizer, this would represent a significant improvement in worldwide nitrogen use efficiency (NUE). It could significantly reduce the ecologically damaging flow of $\mathrm{N}_{\mathrm{r}}$ cascading through the environment noted above while maintaining the same level of $\mathrm{N}$ fertilizer and therefore agricultural productivity.

In addition to reducing the pollution associated with volatile $\mathrm{NH}_{3}$ release into the environment, this process greatly increases the fertilizer value of the manure, thereby increasing NUE and reducing (but probably not eliminating) the need for HB-generated $\mathrm{N}$ fertilizer. By making organic fertilizer more "potent," the proposed process would encourage recycling of organic forms of nitrogen, and the carbon compounds and micronutrients in organic fertilizer would also be of considerable value to maintain soil quality. ${ }^{13}$ 


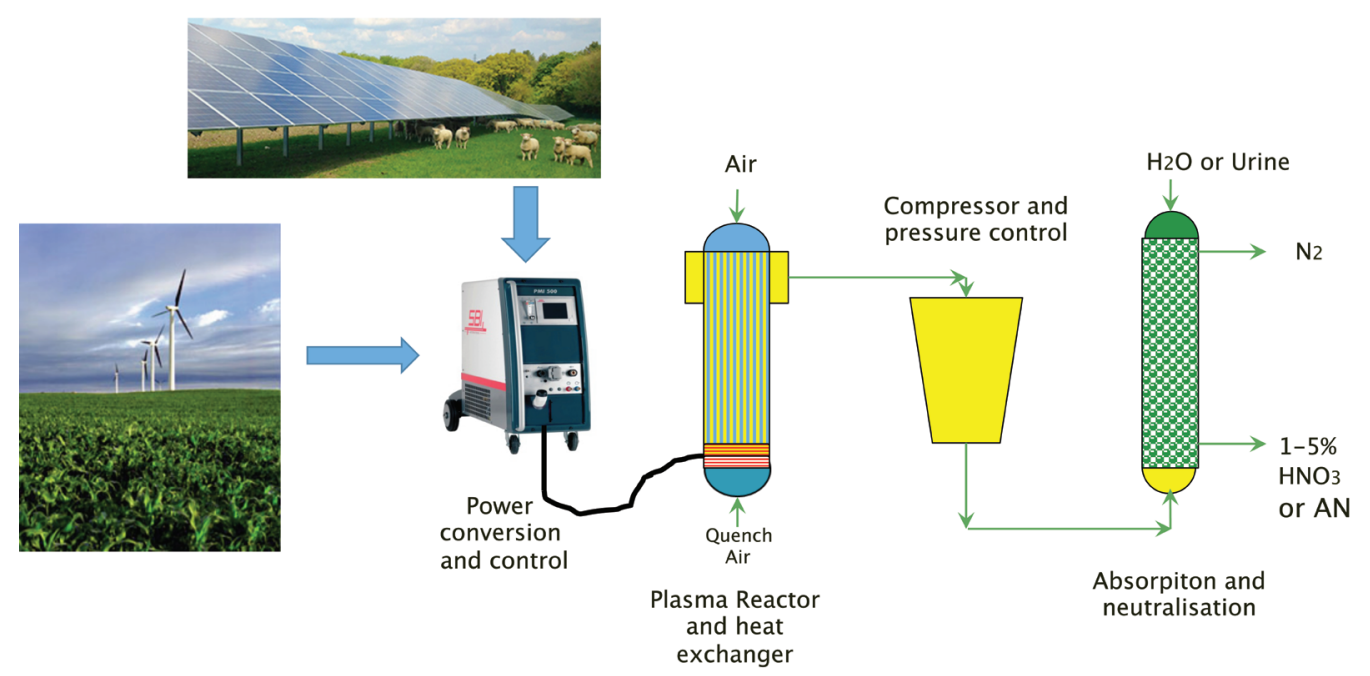

FIG. 4: Sketch of proposed system that is suitable for agricultural application. Powered locally by renewable sources, the air plasma reactor generates $\mathrm{NO}_{2}$ that is absorbed by water or possibly waste livestock urine, creating nitric acid solution or ammonium nitrate (AN) from the $\mathrm{HNO}_{3}$ reaction with $\mathrm{NH}_{3}$ in urine.

One possible application is illustrated in Figure 5. Manure slurry from pigs can of course be captured and used directly as organic fertilizer in the fields, as shown in the top of the figure. However, the manure could lose a significant fraction of its nitrogen in the form of volatile $\mathrm{NH}_{3}$. The $\sim 0.7 \%$ (by slurry mass) of $\mathrm{N}$ in the manure slurry would be reduced to $\sim 0.4 \%$ of $\mathrm{N}$ by the time it is applied to the fields. The lower portion of Figure 5 shows the manure slurry mixed with an appropriate solution of plasma-generated nitric acid, thus forming $\mathrm{NH}_{4} \mathrm{NO}_{3}$ and thereby increasing $\mathrm{N}$ content of the slurry to $1 \%$. The increase in $\mathrm{N}$ content from $0.4 \%$ to $1 \%$ is obviously a significant increase in the slurry's fertilizer value.

\section{WHY USE PLASMA TECHNOLOGY?}

The proposal to use air plasma technology may be surprising because some aspects of the basic idea were proposed and indeed commercially used around the beginning of the 20 th century but abandoned several decades later. The best-known plasma arc process was developed and commercialized in Norway in 1903 by Birkeland and Eyde. ${ }^{2}$ Figure 6 shows a photograph of the original Birkeland/Eyde air plasma arc. In 2011, Dawson and Hilton reported that the energy efficiency of the Birkeland/Eyde process was $\sim 250 \mathrm{GJ} / \mathrm{t} / \mathrm{N} .^{2}$ By $\sim 1920$, the HB-process energy efficiency had reached $\sim 100 \mathrm{GJ} /$ $\mathrm{t} / \mathrm{N}$, thus requiring less than half the energy used in the air plasma process. ${ }^{2}$ Furthermore, the plasma process uses electricity, and at that time, this was most expensive form of energy. Even with relatively inexpensive electricity from hydropower in Norway (or in 


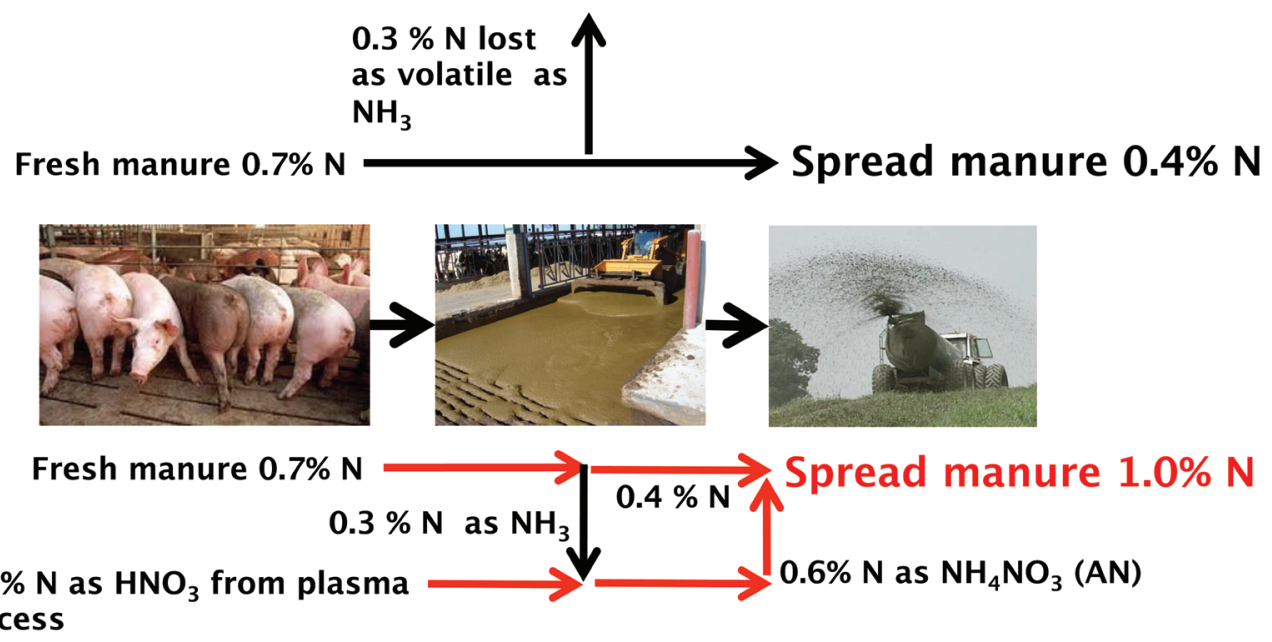

FIG. 5: Comparison of proposed waste acidification scheme (bottom) with conventional organic fertilizer recycling (top). Per kilogram of manure produced, $0.3 \%$ (by mass) of $\mathrm{N}$ is lost as $\mathrm{NH}_{3}$, but in nitric acid acidification, this is trapped as ammonium nitrate and added back to the organic fertilizer before being applied to fields. The difference is a $250 \%$ increase in organic fertilizer nitrogen content.

the US at Niagara Falls, NY), the plasma process was soon abandoned in favor of fossilfuel-powered HB technology. It should be noted that the major problem with the air plasma approach to nitrogen fixation was the cost associated with electricity. The other components of the process used to make nitric acid (the reaction of $\mathrm{NO}$ to $\mathrm{NO}_{2}$, followed by formation of $\mathrm{HNO}_{3}$ in water) were mature, relatively inexpensive, and simple technologies even in 1903.

The present concept differs from early plasma arc technology in at least three important ways. First, energy efficiency of air plasma when creating NO has improved dramatically, with recent results reported to be on the order of $100-150 \mathrm{GJ} / \mathrm{t} / \mathrm{N} .{ }^{14}$ As noted above, the original Birkeland/Eyde process consumed $250 \mathrm{GJ} / \mathrm{t} / \mathrm{N}$ (cf. Fig. 2). On the basis of recent studies, there are sound reasons to show that this can be reduced considerably with more plasma research, as described in greater detail below. One key idea is to exploit nonequilibrium phenomena in the plasma, thus avoiding excessive gas heating and loss of energy efficiency. Another promising direction is to combine heterogeneous catalysis with plasma to increase energy efficiency even further.

Second, the original Birekland/Eyde technology reacted nitric acid with calcium carbonate (limestone; $\left.\mathrm{CaCO}_{3}\right)$, creating calcium nitrate $\left(\mathrm{Ca}\left[\mathrm{NO}_{3}\right]_{2}\right)$ as the fertilizer. The fertilizer manufacturing plants were located at the site of large-scale hydroelectricity, and the fertilizer product ("Norwegian saltpeter") was then shipped to farms. This is therefore similar to the current system for production, storage, and shipping of HBgenerated ammonia-based fertilizer. The present proposal envisions reacting $\mathrm{HNO}_{3}$ with 


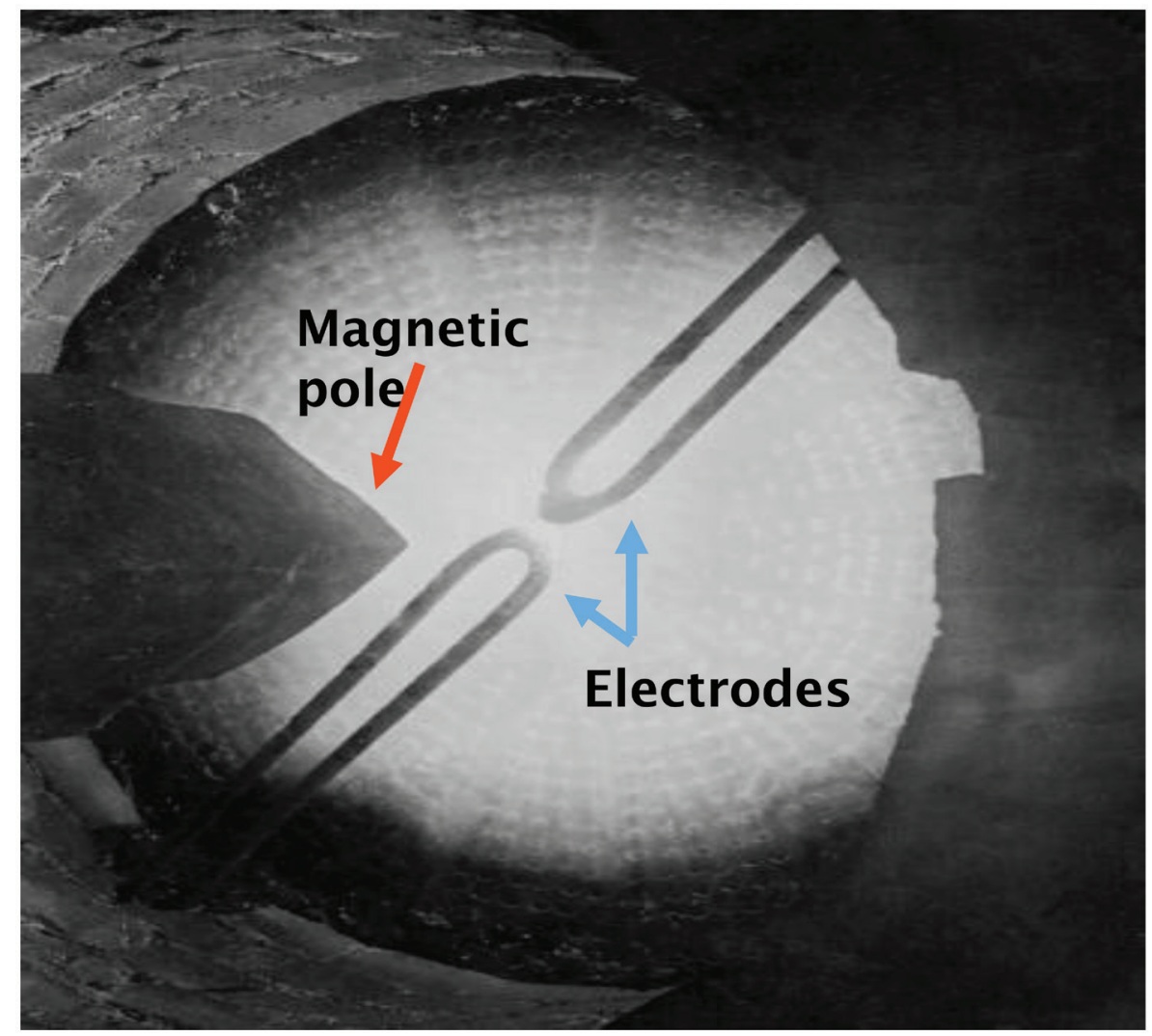

FIG. 6: Original Birkeland/Eyde plasma arc reactor (ca. 1905). The arc forms as an alternating flat hemisphere on both sides of the two electrodes, sustained in the presence of a magnetic field. The arc is burned as a stable white "flame."

$\mathrm{NH}_{3}$ generated locally in organic waste, such as manure, thus creating ammonium nitrate. The key difference is that the present air plasma proposal would consist of many, and probably much smaller, facilities located near both the sources of organic waste and the fields where the organic fertilizer would be applied.

The third difference between this proposal and the original concept is the use of local, renewable sources of energy to sustain the plasma and other components of the process (e.g., pumps, compressors, etc.). The growing worldwide movement toward distributed, renewable energy in the form of electricity, replacing fossil-fuel combustion, suits plasma technology perfectly: Rather than have large, centralized fertilizer manufacturing plants in locations with relatively inexpensive natural gas, requiring product storage and transportation to the distributed to agricultural regions where it is to be used, the present proposal envisions exploiting the naturally distributed nature of renewable electricity generation to create and use $\mathrm{N}_{\mathrm{r}}$ locally and synergistically with organic fertilizer. The plasma process uses only air, water, and electricity as inputs, 
and the technology is relatively simple. Of course, the plasma process envisioned here would require investment in small- to medium-scale renewable energy facilities, such as wind turbines, in addition to the capita and operating costs associated with plasma-based nitric-acid-generating facilities.

Nitric acid is now made commercially by oxidizing $\mathrm{NH}_{3}$, created in $\mathrm{HB}$ manufacturing plants, in the catalytic oxidation process originally developed by Ostwald. ${ }^{4}$ In principle, nitric acid made conventionally could be used to treat organic waste with the same $\mathrm{N}_{\mathrm{r}}$-capturing benefits that we identify here, but there are substantial disadvantages to this option. Nitric acid made conventionally at HB plants would need to be stored and then transported in concentrated form to farms that are not, in general, close to fertilizer plants. The main disadvantage of this option is therefore cost, and the sustainability advantages associated with local generation and use of $\mathrm{N}_{\mathrm{r}}$ via distributed renewableenergy sources would also be lost.

In addition to the benefits in increasing NUE with the use of use air plasma technology, some of the problems identified above (associated with developing world agriculture) could be addressed. In sub-Saharan Africa and parts of South America, fertilizer underuse is acknowledged to be a serious factor in environmental degradation, because low-productivity agriculture requires turning forests and other ecologically fragile areas into crop-growing fields. The soil then loses minerals and organic carbon after agriculture is initiated, and yields drop, requiring the pattern to repeat. ${ }^{6,15}$ As pointed out, ${ }^{16}$ a major challenge in sub-Saharan Africa is the development of a less-capital-intensive method to fix nitrogen that does not require being close to large natural-gas supplies and is less sensitive to the lack of infrastructure such as roads and storage facilities. This would allow a larger number of smaller facilities to provide for local needs. The proposed air plasma technology could help to meet these needs.

\section{REDUCING GLOBAL-WARMING GAS EMISSIONS}

A key problem with all N-based fertilizers is the generation and release of global-warming gases (GHG). Increasing NUE with the proposed process will have a positive impact on this problem by reducing the cascading effect of $\mathrm{N}_{\mathrm{r}}$. As noted by Galloway et al., "The same atom of $\mathrm{N}_{\mathrm{r}}$ can cause multiple effects in the atmosphere, in terrestrial ecosystems, in freshwater and marine systems, and on human health." Partially replacing conventional HB manufacturing plants with the air plasma technology would also significantly, but not dramatically, reduce global $\mathrm{CO}_{2}$ emissions by reducing steam reforming to make $\mathrm{H}_{2}$ to manufacture $\mathrm{NH}_{3}$. Of particular concern is emission of nitrous oxide $\left(\mathrm{N}_{2} \mathrm{O}\right.$ ), because its global-warming potential (on a per-mass basis) is $\sim 300$ times larger than that of $\mathrm{CO}_{2}$. In addition, $\mathrm{N}_{2} \mathrm{O}$ is a potent destroyer of atmospheric ozone. $\mathrm{N}_{2} \mathrm{O}$ is generated by soil microbes when ammonia is converted to nitrate (nitrification), and it is also released in the process of converting nitrate to nitrogen (denitrification). Using nitric acid to acidify manure, thereby trapping otherwise volatile $\mathrm{NH}_{3}$, reduces both nitrification and denitrification and their associated creation of $\mathrm{N}_{2} \mathrm{O}$. It is estimated that between $0.5 \%$ and $3 \%$ of $\mathrm{NH}_{3}$ in nitrification and $\mathrm{NO}_{3}$ in denitrification is diverted 
to $\mathrm{N}_{2} \mathrm{O}$. If the current proposed air plasma system were to be implemented, a significant advantage would be a reduction in $\mathrm{NH}_{3}$ lost to the environment and the resulting reduction in $\mathrm{N}_{2} \mathrm{O}$ emissions. ${ }^{12}$

\section{ENCOURAGING ORGANIC FERTILIZER USE}

The technology proposed here would encourage the use of organic fertilizer because it would increase the N content, a common limitation in organic fertilizer. Several recent studies have shown that agricultural yields from plots using organically grown crops are typically $\sim 75 \%-80 \%$ of values obtained from conventional agricultural methods. ${ }^{17,18}$ Returning macronutrients such as $\mathrm{N}, \mathrm{P}$, and $\mathrm{K}$ in the form of recycled organic waste is desirable in general. It is important to note that recycled organic waste also returns valuable micronutrients to soils. ${ }^{13}$ However, organic forms of fertilizers - manures and crop wastes - are known to have generally lower $\mathrm{N}$ content than that of synthetic fertilizers. It has been reported that at least part of the difference in crop yields is due to lower $\mathrm{N}$ content and the slow rate of conversion of organic $\mathrm{N}$ to mineralized $\mathrm{N}$, which is most immediately useful for plants. ${ }^{17,19}$ Similar points have been are made by Rosen and Allen. ${ }^{20}$ But as Dobermann and Conner point out, ${ }^{21-23}$ a more important limitation of organic fertilizer is at the system scale. It must be recognized that generating organic manure (or promoting biological nitrogen fixation via legume crops) incurs additional costs associated with land and nutrients, among others. Dobermann notes that the key metric is food produced per unit of area-time. ${ }^{21}$ Relying on biological nitrogen fixation has the disadvantage of periodically growing legume crops on relatively large land areas that are therefore unavailable for other crops; the food produced per unit of area-time is therefore reduced. Reducing $\mathrm{NH}_{3}$ losses and adding nitrate to organic waste will encourage more organic waste recycling, because it will be more effective at the crop-system level.

\section{IMPROVING PLASMA TECHNOLOGY}

For the proposed technology to become a practical reality, significant improvements in energy efficiency of the air plasma device are needed, such as a reduction in the GJ/t/ $\mathrm{N}_{\mathrm{r}}$ created. A common misconception is that air plasma generates nitric oxide primarily through heating air to the point that nitrogen reacts thermally with oxygen, in analogy with reactions occurring in naturally occurring atmospheric lightning. ${ }^{24}$ If that were true, thermodynamic conversions would predict the upper limit of NO formation at the temperature created in the plasma. For example, Birkeland and Eyde ${ }^{2}$ observed an outlet composition of $\sim 2 \%$ NO (by volume) in the air flowing through their device. The thermodynamic equilibrium conversion of $2 \% \mathrm{NO}$ in air at atmospheric pressure corresponds to a temperature of $\sim 3500^{\circ} \mathrm{K}$. If all of the treated air in the process was heated to $3500^{\circ} \mathrm{K}$, it would require $\sim 450-500 \mathrm{GJ} / \mathrm{t} / \mathrm{N}$. In fact, the measured air temperature leaving the device would be closer to $700^{\circ} \mathrm{K}$, and the corresponding net energy efficiency would be determined to be $\sim 250 \mathrm{GJ} / \mathrm{t} / \mathrm{N}$, as noted above. These results already demon- 
strated in 1903 that the process is not determined solely by thermodynamic equilibrium conversions.

In the intervening century, considerable additional research on the plasma science of $\mathrm{N}_{2}$ conversion to NO has been conducted, and it is clear that the chemical kinetics of NO formation in some air plasma devices can be dominated by nonthermal, nonequilibrium kinetics. ${ }^{25}$ That is, electrons in the plasma are considerably hotter than the neutral gas, and they can selectively excite various higher-level vibrational and electronic transitions. $\mathrm{N}_{2}$ dissociation to form $\mathrm{NO}$ is the rate-limiting step, because $\mathrm{O}_{2}$ dissociates relatively easily. Under the right conditions, rates of collisional and radiative deexcitation of these excited states are too slow to reestablish a Boltzmann distribution of state densities. The rate coefficient for $\mathrm{O}$ reacting with $\mathrm{N}_{2}$ to form $\mathrm{NO}$ is much higher if the $\mathrm{N}_{2}$ population is enriched in higher vibrational or electronic quantum states at a given temperature. Researchers have concluded that this nonequilibrium excitation of higher vibrational and/or electronic states of $\mathrm{N}_{2}$ in the plasma is probably responsible for the observed elevated rates and increased overall energy efficiencies in converting air to NO. In effect, the plasma can channel a greater fraction of applied electrical energy into creating highly reactive excited states than it would if all energy levels were Boltzmann-distributed at the nominal gas temperature. It is also known that net $\mathrm{NO}$ conversions are strongly affected by the reverse reaction of $\mathrm{NO}$ returning to $\mathrm{N}_{2}$ and $\mathrm{O}_{2}$. If $\mathrm{NO}$, once formed, is be quickly "quenched" before it can undergo the reverse reaction, conversions are higher.

Overall energy efficiencies of plasma systems also depend sensitively on recycling excess heat generated in the process, for example, by efficient feed-effluent heat exchange. However, the details of how these factors work in practical devices and their associated manufacturing plants, and how far they can be optimized, are certainly not fully understood. Clearly, this is a topic of important future research. Another area that promises to improve energy efficiency is the use of catalysis combined with plasma.

In any case, recent experiments have shown that conversion efficiencies of $30 \mathrm{GJ} /$ $\mathrm{t} / \mathrm{N}$ or even lower are possible but are not yet under industrially relevant conditions. ${ }^{14}$ Air plasma reactors that can be used in the field have so far achieved reported efficiencies of $\sim 100-150 \mathrm{GJ} / \mathrm{t} / \mathrm{N}$, but laboratory results suggest that this can be considerably improved. ${ }^{14}$

\section{VII.SUMMARY AND CONCLUDING REMARKS}

One of the most challenging problems facing mankind over the next several decades is finding ways to increase food production while greatly reducing the associated damaging environmental impacts of large-scale agriculture. An important element in this challenge is to significantly increase nitrogen utilization efficiency. We propose an air plasma technology that has the potential to substantially reduce human perturbation to the global nitrogen cycle. Air plasmas create NO that can be readily oxidized in air to form $\mathrm{NO} 2$ and then to nitric acid by water absorption. Nitric acid can trap volatile $\mathrm{NH} 3$ created when bacteria degrade organic waste. The resulting NH4NO3 contained in the organic waste increases the nitrogen value of the organic fertilizer and reduces the dam- 
aging environmental effects of NH3 emission to the atmosphere. Distributed, renewable electricity generation can be used to power the plasma. In this vision, the air plasma technology complements conventional Haber-Bosch NH3 manufacturing technology, thus reducing the need for synthetic fertilizers made in centralized plants far from their use. Successful implementation of plasmas for this application could serve as a model for other plasma-based electro-catalytic applications in large scale industrial chemical processing. The technology is still in its infancy, but the need is great and the potential to make a major contribution to solving some important, emerging world problems is excellent.

\section{REFERENCES}

1. Smil V. Enriching the earth. Cambridge, MA: MIT Press; 2001.

2. Dawson CJ, Hilton J. Fertilizer availability in a resource-limited world: Production and recycling of nitrogen and phosphorus. Food Policy. 2011;36:S14-22.

3. Erisman JW, Sutton MA, Galloway J, Klimont Z, Winiwarter W. How a century of ammonia synthesis changed the world. Nature Geosci. 2008;1:636-9.

4. Smil V. Nitrogen and food production: Proteins for human diets. AMBIO J Human Environ. 2002;31(2):126-31.

5. Fowler D, Pyle JA, Raven JA, Sutton MA. The global nitrogen cycle in the twenty-first century. Philos Trans R Soc Lond B Biol Sci. 2013;368:20130164.

6. Sutton MA, Bleeker A, Howard CM, Bekunda M, Grizzetti B, de Vries W, van Grinsven HJM, Abrol YP, Adhya TK, Billen G, Davidson EA, Datta A, Diaz R, Erisman JW, Liu XJ, Oenema O, Palm C, Raghuram N, Reis S, Scholz RW, Sims T, Westhoek H, Zhang Y. Our nutrient world: The challenge to produce more food and energy with less pollution. Edinburgh, UK: Centre for Ecology \& Hydrology; 2013.

7. Galloway JN, Aber JD, Erisman JW, Seitzinger SP, Howarth RW, Cowling EB, Cosby BJ. The nitrogen cascade. BioSci. 2003;53(4):341-56.

8. Rockström J, Steffen W, Noone K, Persson Å, Chapin FS III, Lambin E, Lenton TM, Scheffer M, Folke C, Schellnhuber H, Nykvist B, de Wit CA, Hughes T, van der Leeuw S, Rodhe H, Sörlin S, Snyder PK, Costanza R, Svedin U, Falkenmark M, Karlberg L, Corell RW, Fabry VJ, Hansen J, Walker B, Liverman D, Richardson K, Crutzen P, Foley J. Planetary boundaries: Exploring the safe operating space for humanity. Ecology Soc. 2009;14(2):32.

9. Roy BC, Chattopadhyay GN, Tirado R. Subsidising food crisis synthetic fertilisers lead to poor soil and less food. New Delhi, India: Greenpeace India; 2009.

10. Inman M. The fracking fallacy. Nature. 2014;516:28.

11. Giddey S, Badwal SPS, Kulkarni A. Review of electrochemical ammonia production technologies and materials. Int J Hydrogen Eng. 2013;38:14576-94.

12. Fangueiro D, Hjorth M, Gioelli F. Acidification of animal slurry: a review. J Environ Manage. 2015;149:46-56.

13. Jones DL, Cross P, Withers PJA, DeLuca TH, Robinson DA, Quiullam RS, Harris IM, Chadwick DR, Edwards-Jones G. Nutrient stripping: the global disparity between food security and soil nutrient stocks. J Appl Ecology. 2013;50:851-62.

14. Ingels R, inventor. Energy efficient process for producing nitrogen oxide. Norwegian patent WO 2012150865 A1. 2012 Nov 12. 
15. Laurance WF, Sayer J, Cassman KG. Agricultural expansion and its impacts on tropical nature. Trends Ecol Evol. 2014;29(2):107-16.

16. Buluswar S, Friedman Z, Mehta P, Mitra S, Sathre R. Food Security and Agricultural Development. In: The 50 breakthroughs study. Berkeley, CA: LIGTT Institute for Globally Transformative Technologies; 2014.

17. Seufert V, Ramankutt N, Foley JA. Comparing the yields of organic and conventional agriculture. Nature. 2012;485:229-32.

18. de Ponti T, Rijk B, van Ittersum MK. The crop yield gap between organic and conventional agriculture. Agricult Syst. 2012;108:1-9.

19. Berry PM, Sylvester-Bradley R, Philipps L, Hatch DJ, Cuttle SP, Rayns FW, Gosling P. Is the productivity of organic farms restricted by the supply of available nitrogen? Soil Use Manage. 2002;18:248-55.

20. Rosen CJ, Allan DL. Exploring the benefits of organic nutrient sources for crop production and soil quality. Hort Technol. 2007;17(4):422-430.

21. Dobermann A. Getting back to the field. Nature. 2012;485:176.

22. Conner DJ. Organically grown crops do not a cropping system make and nor can organic agriculture nearly feed the world. Field Crops Res. 2013;144:145-7.

23. Connor DJ. Organic agriculture cannot feed the world. Field Crops Res. 2008; 106:187-90.

24. Schumann U, Huntrieser H. The global lightning-induced nitrogen oxides source. Atmos Chem Phys. 2007;7:3823-907.

25. Fridman G. Plasma Chemistry. Cambridge, MA: Cambridge University Press; 2012. 